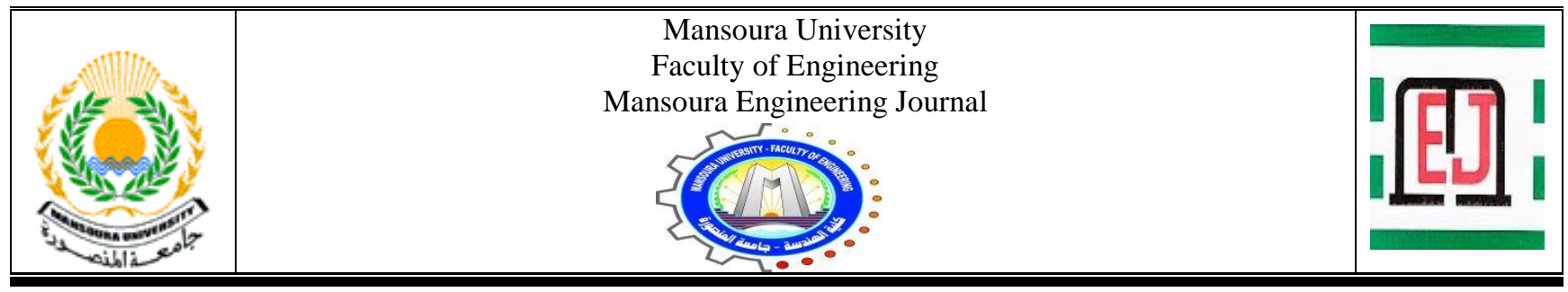

\title{
Induction Motor Drive Using Fractional-Order Proportional Integral Derivative (FOPID) Controller Based on Nelder-Mead and Grey Wolf Optimizers
}

\author{
Mohamed Said*, Mostafa A. Elhosseini and Eid Abdelbaki Gouda
}

\begin{tabular}{|lr|}
\hline KEYWORDS: \\
Induction Motor Drive, \\
FOPID controller, \\
Nelder-Mead & optimizer, \\
Grey Wolf & Optimizer, \\
induction & motor \\
Simulink, three cases \\
study
\end{tabular}

Abstract - Induction motors are widely used in industrial applications due to their advantages over dc motors in terms of low cost, low maintenance, high performance, and high power density. This article aims to achieve constant speed control of the induction motor (IM) and improves the motor performance using a Fractional-order PID controller (FOPID). The FOPID controller contains five important variables coefficients. They are named as follows: proportional operator $(\mathrm{Kp})$, integral operator $(\mathrm{Ki})$ derivative operator $(\mathrm{Kd})$, integral of fractional-order $(\lambda)$ and the derivative of fractional-order $\mu$. The performance of any controller depends mainly on the chosen values of the aforementioned operators $(K p, K i, K d, \lambda, \mu)$ so one of the main objectives of this paper how to optimize the values of these five parameters to improve the system performance. Actually there are many methods to achieve the optimization problem but a two selected optimizers (Grey Wolf Optimizer, and Nelder-Mead) are chosen in this paper due their nature which make them more suitable for the presented problem. Three cases study of the induction motor integrated with the proposed controllers are simulated based on Matlab SIMULINK and the obtained results are discussed in details. The obtained results in all the cases ensured that the proposed FOPID controller introduced always the better performances indices which make it favorably recommended instead of other conventional controllers.
Received: (29 January, 2021) - Revised: (08 June, 2021) - Accepted: (10 June, 2021)

Corresponding Author: Mohamed Said Essa, researcher at Faculty of Engineering, Mansoura University, Electrical Engineering, (email: Eng_mohamedsaed.2007@yahoo.com).

Prof. Dr. Mostafa A. Elhosseini, professor at Department of Computers and Systems Engineering at Faculty of Engineering, Mansoura University, (email: melhosseini@gmail.com)

Assoc. Prof. Dr. Eid Abdelbaki Gouda, associate professor at Electrical Engineering Department, Faculty of Engineering, Mansoura University, (email: eaidgoda@mans.edu.eg.)

\section{INTRODUCTION}

I NDUCTION motors are the most popular electrical systems in modern industries and are known for their many benefits which are high efficiency, low costs, low maintenance needs, and simple construction[1]-[3]. The induction motor (IM) is a kind of AC motors where the electromagnetic power is passed from the main windings to secondary windings through inductive coupling, the two windings being isolated by an air gap. This power is normally transferred from the stator windings to the rotor windings in a three-phase motor to convert electrical power to mechanical power [4], [5]. 
When the AC voltage source applied to the motor' stator terminals a rotation magnetic field will be produced in the stator windings. Also in the rotor side there will be induction currents and voltages will be created by induction concept. The motor will produce a suitable torque generated by the interaction between the stator and rotor fields which push the motor speed to startup and its value will increase gradually to reach near to the nominal motor synchronous speed [6]. The speeds of the actual rotors have to be less than synchronous speeds, so the relationship between the synchronous speed and motor speed is called slip. When the rotor speed decreases below synchronous speed, the rotating magnetic fluxes produce more currents in the windings and generate more torque. Under load, the speed of the IM decreases and the slip raises enough to produce enough torque to drive the load. For this purpose, IMs are also called as asynchronous motors [7].

Due to the important of induction motor drive many researchers proposed several techniques some of them are conventional and others are advanced among of them one called scalar control (SC) method which has been extensively used due to it possesses a simple design, easy to execute, and costless [8]-[10]. One of the most widely used and widespread techniques in SC is Voltage/frequency (V/f) which keeps the ratio constant between variation terminal voltage and frequency to avoid the saturation of the magnetic flux[11]. The conventional controllers such as Proportional Integral (PI) and Proportional Integral Derivative (PID) can be sometimes recommended due to their special advantages. For example the PI controller has simple design, improving damping, reducing maximum overshoot, reducing bandwidth, and increasing rise time. However, the PI controller sometimes fails to maintain motor reference speed specially in existing of interference or system disturbance [12]. Therefore, there was needed to use other modified control techniques like a PID [13], or FOPID controllers. The FOPID controller contains five important variables coefficients. They are named as follows: - proportional operator $\left(K_{p}\right)$, integral operator $\left(K_{i}\right)$, derivative operator $\left(K_{d}\right)$ integral of fractional-order $\lambda$ and the derivative of fractional-order $\mu$. It is noted that in case of PID and PI controllers the values of each $\lambda$ and $\mu$ parameters is equals 1 . The performance of any controller depends mainly on the chosen values of the aforementioned operators $\left(K_{p}, K_{i}\right.$, $\left.K_{d}, \lambda, \mu\right)$ so one of the main objectives of this paper how to optimize the values of these five parameters to improve the motor performance and enhancing its speed control. It was found several techniques (conventional or non-conventional) to optimize the five parameters. Among of them some classic methods such as Ziegler Nichols (ZN) [14], Cohen coon [15], and Chien-Hrones-Reswick [16]. Accuse of the continuous development in previous control technique methods especially in the last two decades and the invention of the heuristic approaches, the systems performances were improved rapidly. Some of familiar examples of these approaches are Genetic Algorithms (GA) [17], Particle Swarm Optimization [18], and Grey wolf Optimization (GWO). In this paper the GWO is proposed to apply due to its several merits such as it takes into account the global and local search possibility, hunting activity, and the social grey wolves swarm order. Also this technique is considered very simpler to utilize and converges more quickly [19]. PID Tuner is another technique which can be used for optimization process [20]. The tuning objective in this method is to achieve better behavior and robustness for the used system. In Ref.[21], the authors presented a detail comparison between fuzzy PID and classical PID controllers. Form the presented study it was proved that fuzzy controller introduced higher performance than the conventional PID controller. For example the rising time of fuzzy PID is about $0.08 \mathrm{sec}$ which is considered shorter than the time in case of conventional one (about $0.2 \mathrm{sec}$ ). Attia et al. [22] presented two different fuzzy controller adapted for switching filter compensation approach to improve power quality and system stability and its power factor. The used controllers are dealing with multi-loop dynamic error. The presented methodology granted minimal harmonica distortion. Abdelwanis et al. [23] introduced a details study about fuzzy controller adapted for six-phase Induction Motor. The conventional and fuzzy PID controller is designed and compared. The presented results proved that the fuzzy controller is recommend for the ensuring good system stability more than the classical one.

As mentioned before there are many methods to achieve the optimization problem of the FOPID five parameters controller but two only selected optimizer GWO, and NelderMead (NM) optimization due their nature which make them more suitable for the presented problem[24],[25]. There will be a three different cases study including three different induction motors system rating with PI, PID and FOPID controllers will be studied in the current paper.

The paper is organizes as follows; system induction motor modeling and SIMULINK and fractional order PID controller are presented in sections II and III. The used optimizer techniques are introduced in section IV. After that, definitions of important control parameters sections are discussed in details. Finally the paper was ended by results, analysis and conclusion.

\section{SYSTEM INDUCTION MOTOR MODELING AND SIMULINK}

Three induction motor models will be presented with their Simulink as follow:-

\section{A. Case No.1:}

Here three phase induction motor represented by its transfer function only [26] is given by equation 1 .

$$
G_{P}(S)=\frac{2}{4 S^{2}+2 S+1}
$$

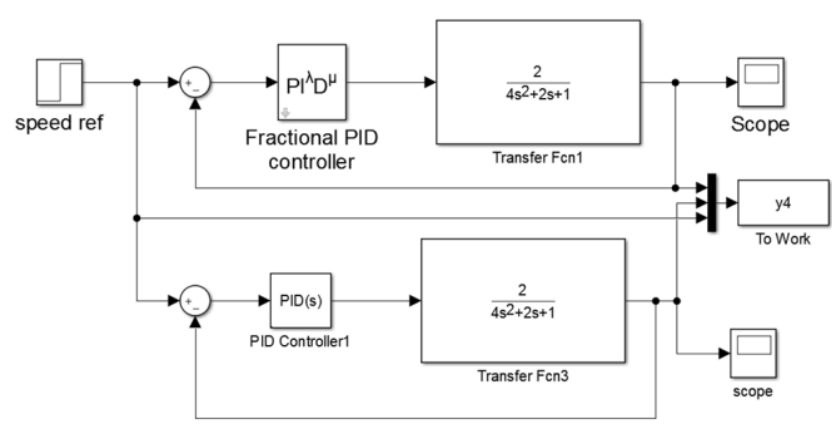

Fig. 1. Matlab Simulink modeling for Case 1 
The Matlab Simulink included the motor transfer function with two different controllers (PID and FOPID) are shown in Fig1. The presented simulated system is considered a closed loop speed controller. The input signal is a unit step function which corresponding to the motor speed event.

\section{B. Case No. 2}

Another induction motor is used in this paper. The motor data in this case is defined as four-pole squirrel-cage threephase induction motor with stator voltage about $120 / 208 \mathrm{v}$, a nominal speed is $1385 \mathrm{rpm}$, and the nominal current is $0.67 \mathrm{~A}$ and the corresponding transfer function is given by equation(2) [27].

$$
G_{P}(Z)=\frac{-0.001473 Z^{3}+0.002844 Z^{2}-0.001529 Z+0.002449}{Z^{4}-0.9471 Z^{3}-0.2428 Z^{2}-0.2336 Z-0.05288}
$$

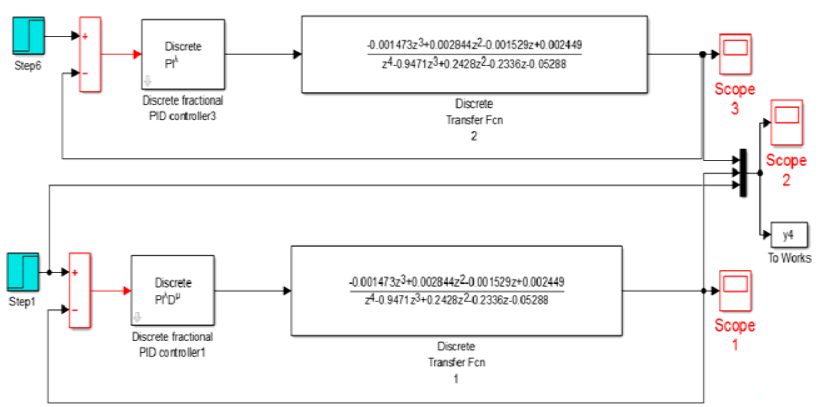

Fig. 2. Matlab Simulink modeling for Case 2

The system modeling with the used controllers are depicted in Fig2

\section{Case No. 3}

The motor modeling in this case will based on the $\mathrm{dq}$ model equations [28] the flux linkages, the voltage equations of the stator, and rotor reference frame on the dq-axis can be written as follows:

$v_{d s}=R_{s} i_{d s}-\omega \lambda_{q s}+\frac{\mathrm{d} \lambda_{d s}}{d t}$

$v_{q s}=R_{s} i_{q s}-\omega \lambda_{d s}+\frac{\mathrm{d} \lambda_{q s}}{d t}$

$v_{d r}=R_{r} i_{d r}+\left(\omega-\omega_{r}\right) \lambda_{d r}+\frac{\mathrm{d} \lambda_{d r}}{d t}$

$v_{q r}=R_{r} i_{q r}+\left(\omega-\omega_{r}\right) \lambda_{q r}+\frac{\mathrm{d} \lambda_{q r}}{d t}$

$\lambda_{d s}=L_{s} i_{d s}-L_{m} i_{d r}$

$\lambda_{q s}=L_{s} i_{q s}-L_{m} i_{q r}$

$\lambda_{d r}=L_{r} i_{d r}-L_{m} i_{d s}$

$\lambda_{q r}=L_{r} i_{q r}-L_{m} i_{q s}$

The electromagnetic torque $T_{e}$, and the corresponding arbitrary rotor speed $\omega_{\mathrm{r}}$ can be determined as follows:

$T_{e}=\frac{3 p}{4}\left(i_{q s} \lambda_{d s}-i_{d s} \lambda_{q s}\right)$ $\omega_{r}=\int \frac{2 P}{J}\left(T_{e}-T_{L}\right)$

The equations from 3 to 12 are simulated in Matlab Simulink and shown in Fig3. And also the block diagram of the induction motor with the proposed FOPID controller connected with Voltage Source Inverter (VSI) are presented in Fig4. The overall Simulink for the used system with the different PI, PID, FOPID controllers and VSI are shown in Figures 5:9.

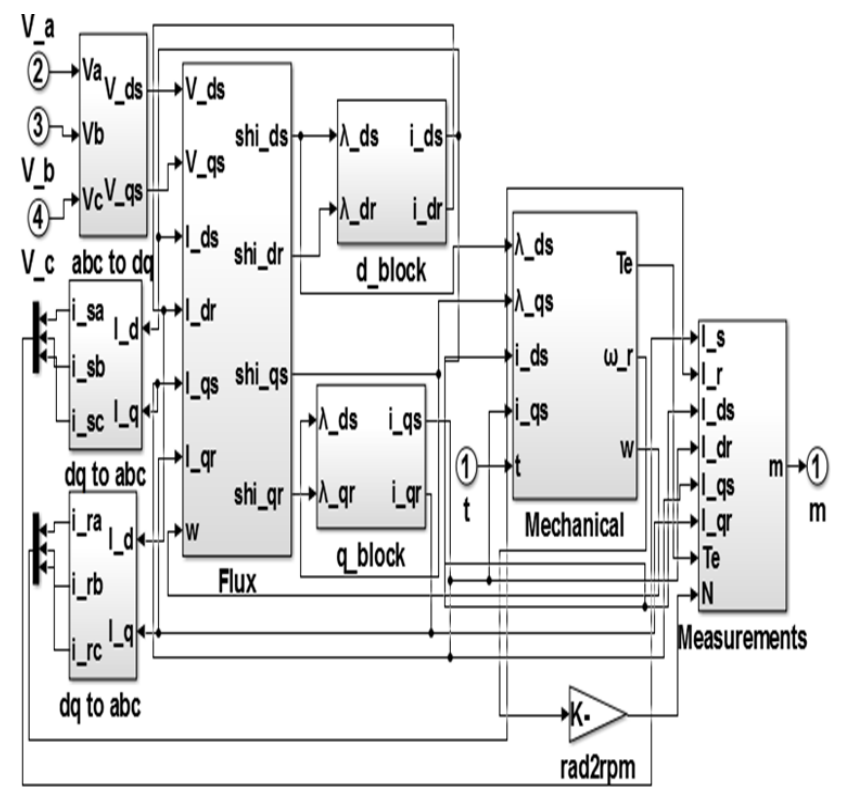

Fig. 3. Simulink of the Three Phase Induction Motor Dynamic Model

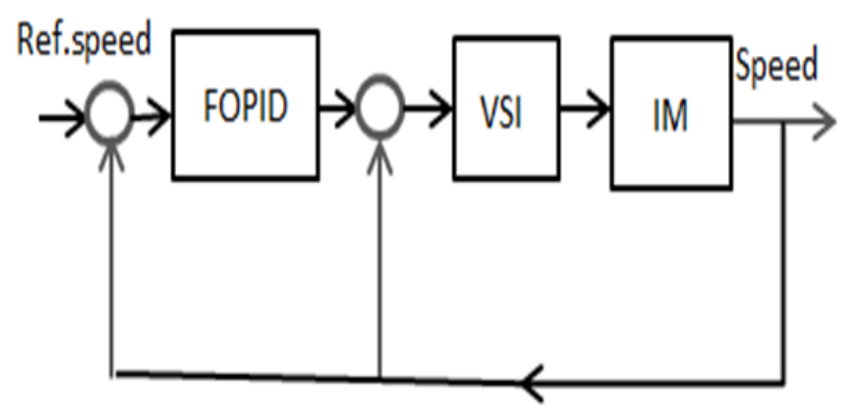

Fig. 4. Block Diagram of the induction Motor with FOPID controller with Voltage Source Inverter (VSI)

A simple three-phase inverter is prepared by Simulink 'Switch', 'Gain' and 'Sum' blocks depended on the relationship between phase voltages and pole voltages as in Figure 9[29], [30]. Note that one of the switch inputs is linked to the signal produced by the SPWM signal generator. PWM switching approaches are generally utilized to adjust the switches of voltage source inverters. 


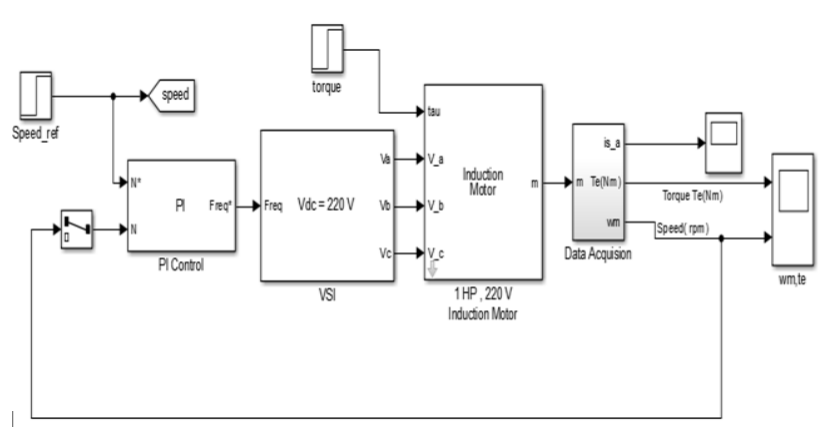

Fig. 5. Simulink of the motor, VSI and PI controller

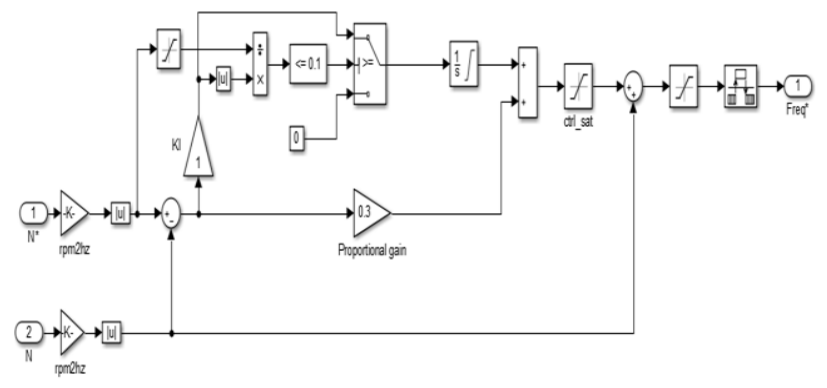

Fig. 6. PI controller

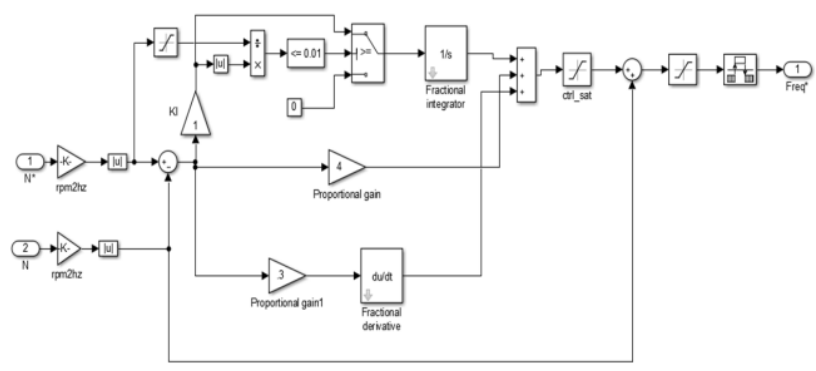

Fig. 7. PID controller

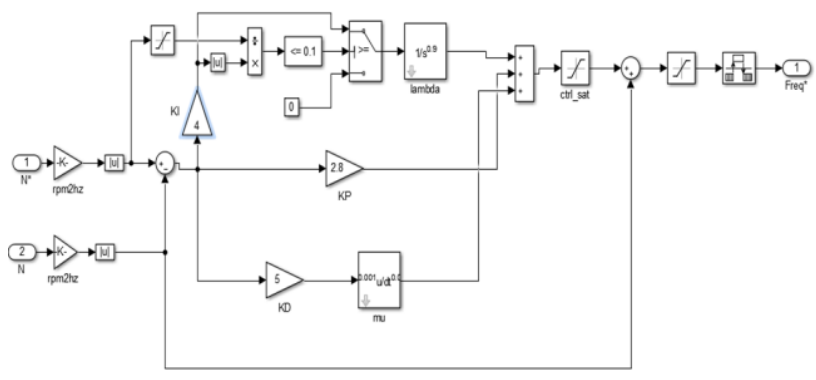

Fig. 8. FOPID controller

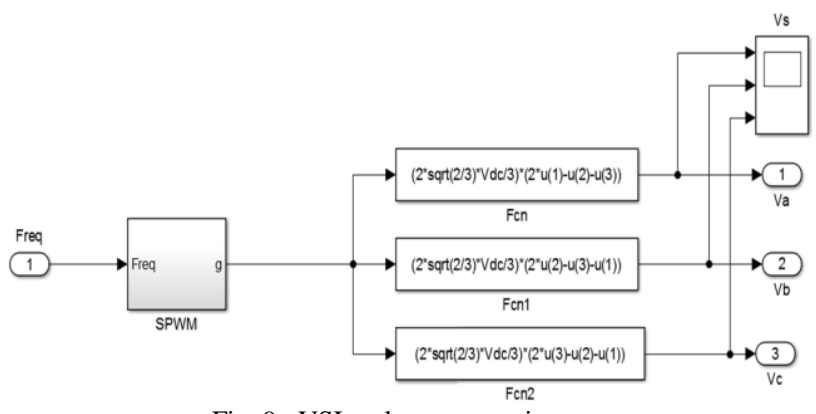

Fig. 9. VSI: voltage source inverter

\section{FRACTIONAL ORDER PID CONTROLLER}

The FOPID is an extension of the PID controller widely utilized in industrial systems. The FOPID is dependent on fractional calculus so provides good behavior of dynamical systems and less sensitivity to varying components in a controlled system. a closed-loop system for the controller corrects the error between response value and set point value to achieve the desired output. The transfer equation of the FOPID controller as follows:-

$G_{c}(s)=K_{p}+\frac{K i}{s^{\lambda}}+K_{d} s^{\mu}$

Five elements, $\left(K_{p}, K_{i}, K_{d}, \lambda, \mu\right)$ as mentioned before characterize the fraction controller behavior Therefore, the relation between the conventional PI, PID and the FOPID is illustrated in Fig 10. It is clear that the FOPID included in its behavior the conventional PI, PID this is occur when set $\lambda$, and $\mu$ equals 1 .

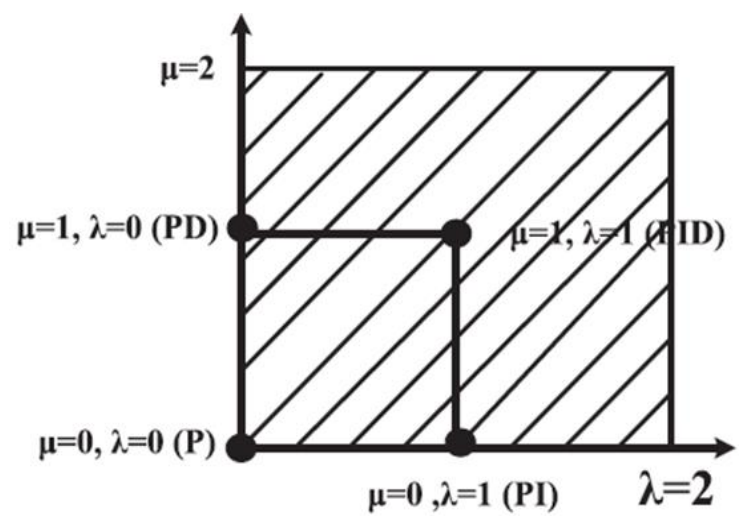

Fig. 10. FOPID Controller [25]

\section{USED OPTIMIZER TECHNIQUES}

\section{A)Nelder-Mead optimization}

This optimizer is integrated in MATLAB tool box called by the command fpid_optim and has the following graphical user interface presented in Fig. 11[31].

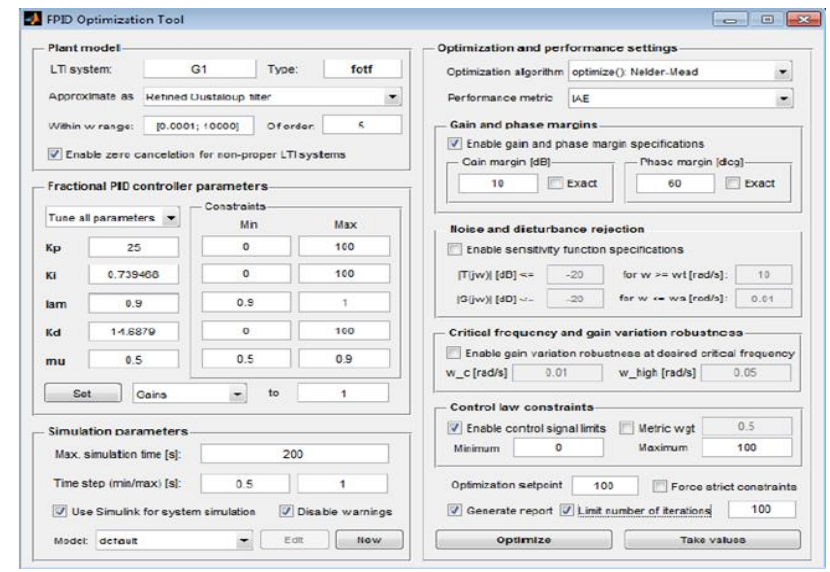

Fig. 11. FOPID optimization tool integrated with Nelder-Mead 
The general steps of controller design as follows:-

- Choose the correct frequency range.

- Choose controller gain/exponent constraints.

- Choose control system constraints based on frequency domain analysis of the open loop.

- Specify the correct control saturation values of the actuator.

- Choose the suitable performance metric method.

For more details about this technique are found in Ref.[31].

\section{B) Grey Wolf Optimization ( $G W O$ )}

GWO technique is considered as one the meta-heuristic optimizers. It simulated the lift style of the group of grey wolves (social hierarchy and hunting mechanism). Also, it described the natural process of grey wolves' life style and the mathematical equations of GWO were modeled based on this simulation. Flowchart of the GWO algorithm is shown Fig. 12 [32]

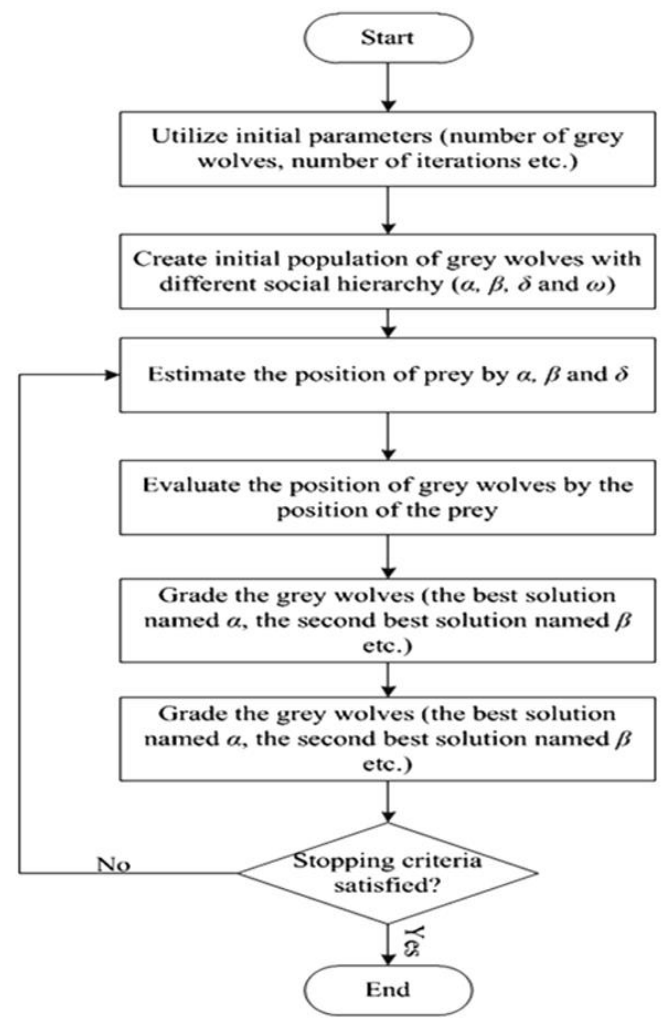

Fig. 12. Flowchart of the GWO algorithm [32]

\section{DEFINITIONS OF IMPORTANT CONTROL PARAMETERS}

Some controller performance indices should be defined clearly to be used during the evaluation process of the behavior of the controller responses. The most commonly chosen parameters are shown in Fig. 13. And will be described as follows:-

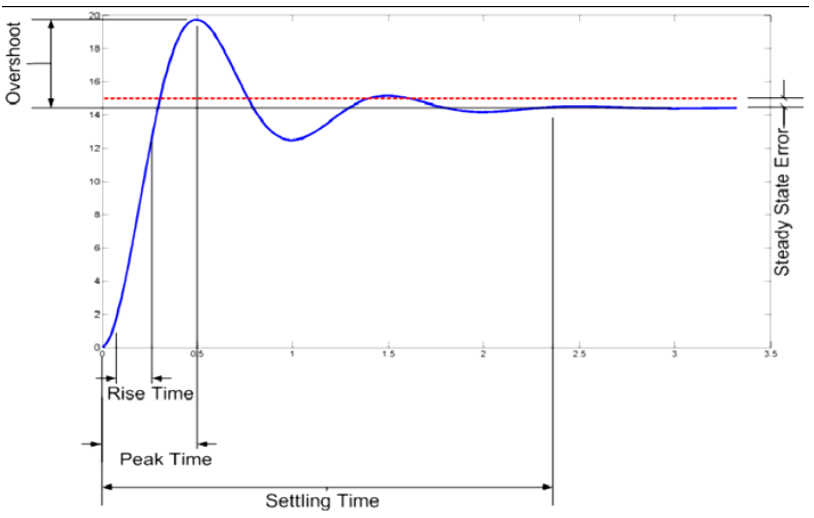

Fig. 13. commonly chosen parameters [33]

1. Rise Time (tr): the time required for the signal to reach $90 \%$ of the final value.

2. Peak Time (tp) - the time required for reaching its maximal value.

3. Overshoot $=(\max$ value - final value $) /$ final value $* 100$.

4. Settling Time (ts): The time required to be bounded to within a tolerance of $\mathrm{x} \%$ of the steady state value.

These indices will be used to compere between the different used controllers during the study.

\section{RESULTS AND ANALYSIS}

In this section for each case study the GWO or NelderMead optimizer is used to find the best controller parameters values then the Matlab Simulink will be executed to obtain the corresponding output results

\section{A)Case No.1:}

Table 2 presents comparison between PID tuning parameters using the auto tuning and FOPID parameters using Nelder-Mead tuning. While Table 3 introduces final brief comparison between PID and FOPID controllers performance indices (rise time, settling time, peak overshot)

The output Simulink results are shown in Fig 14. It is obvious that the controller performance with induction motor in case of using FOPID with Nelder -Mead optimizer introduced better performances indices such as minimum rising time is equal $(0.061 \mathrm{sec})$ and reduced the settling period $(0.1 \mathrm{sec})$ so the motor performance in this case is more efficient than using PID.

TABLE 2

COMPARISON BETWEEN PID TUNING PARAMETERS USING THE AUTO TUNING AND FOPID PARAMETERS USING NELDER -MEAD

\begin{tabular}{l||l||l||l||l||l} 
& \multicolumn{1}{c||}{$\boldsymbol{K}_{\boldsymbol{p}}$} & \multicolumn{1}{|c||}{$\boldsymbol{K}_{\boldsymbol{i}}$} & $\boldsymbol{\lambda}$ & \multicolumn{1}{c|}{$\boldsymbol{K}_{\boldsymbol{d}}$} & $\boldsymbol{\mu}$ \\
\hline FOPID & 28 & 25 & 0.92 & 94 & 0.96 \\
\hline PID [26] & 11.27 & 0.709 & & 15.84 &
\end{tabular}

TABLE 3

COMPARISON BETWEEN PID AND FOPID CONTROLLER PERFORMANCE INDICES

\begin{tabular}{l||c||c||c} 
controllers & $\begin{array}{c}\text { Rise } \\
\text { period(sec) }\end{array}$ & $\begin{array}{c}\text { Settling } \\
\text { Period(sec) }\end{array}$ & $\begin{array}{c}\text { Peak } \\
\text { Overshot }\end{array}$ \\
\hline FOPID & 0.061 & 0.1 & 0 \\
\hline PID [26] & 0.28 & 0.4 & 0
\end{tabular}




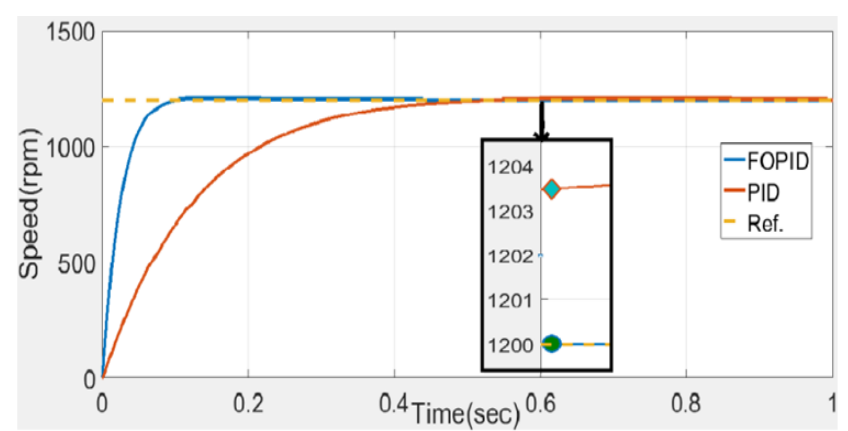

Fig. 14. Comparison of response FOPID, and Single-loop PID

\section{B) Case No. 2}

The same procedure will be applied for the second case study. Table 4 and Table 5 presented the optimal tuning parameters and the performance indices respectively. Also it is found that the FOPID gave the better control performance where its rise time about $0.045 \mathrm{sec}$ and the settling time is $0.1 \mathrm{sec}$ which ensures again its behavior is better than the other FOPI controller. The obtained results are shown in Fig 15.

TABLE 4

COMPARISON BETWEEN FOPI AND FOPID PARAMETERS USING NELDER -MEAD

\begin{tabular}{l||c||c||c||c||c} 
& $\boldsymbol{K}_{\boldsymbol{p}}$ & $\boldsymbol{K}_{\boldsymbol{i}}$ & $\boldsymbol{\lambda}$ & $\boldsymbol{K}_{\boldsymbol{d}}$ & $\boldsymbol{\mu}$ \\
\hline FOPID & 80 & 98 & 0.97 & 6.8 & 0.06 \\
\hline FOPI [27] & 5.2 & 10.7 & 0.893 & 0 &
\end{tabular}

TABLE 5

COMPARISON BETWEEN FOPI AND FOPID CONTROLLER PERFORMANCE INDICES

\begin{tabular}{l||c||c||c} 
controllers & $\begin{array}{c}\text { Rise } \\
\text { period(sec) }\end{array}$ & $\begin{array}{c}\text { Settling } \\
\text { Period(sec) }\end{array}$ & Peak Overshot \\
\hline FOPID & 0.045 & 0.1 & 0 \\
\hline FOPI [27] & 0.9 & 1.2 & 0
\end{tabular}

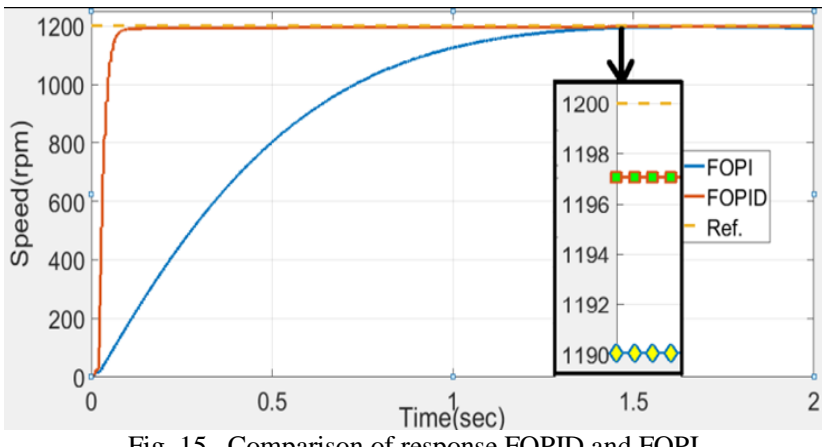

Fig. 15. Comparison of response FOPID and FOPI

\section{C) Case No. 3:}

In this case complete details modeling of the induction motor was implemented in Matlab Simulink as mentioned before in section II, also here three different controllers PI, PID and FOPID are used.

\section{1) Operation under no-load}

Here it is assumed that the motor is run under no-load (it means load torque equals zero) and the required reference speed equals $1600 \mathrm{rpm}$. And after applying the proposed control strategy the obtained results were compared in tabular form as shown in Tables 6-7 and Figs.16-18.

The analysis of the obtained results showed that the settling time is improved from 2.75 to 0.9 in case of using PID controller instead of PI controller. A higher improvement is obtained at using FOPID controller which reached to 0.275 as shown in Table 6. Also it was noted that there is another higher improvement for the rise time from 0.65 to 0.6 and from 0.6 to 0.225 . The same notes for the signal overshoot.

TABLE 6

COMPARISON BETWEEN PID TUNING PARAMETERS USING THE AUTO TUNING AND FOPID PARAMETERS USING GREY WOLF OPTIMIZATION

\begin{tabular}{l||c||c||c||c||c} 
& $\boldsymbol{K}_{\boldsymbol{p}}$ & $\boldsymbol{K}_{\boldsymbol{i}}$ & $\boldsymbol{\lambda}$ & $\boldsymbol{K}_{\boldsymbol{d}}$ & $\boldsymbol{\mu}$ \\
\hline FOPID & 28 & 4 & 0.9 & 0.9 & 0.001 \\
\hline$P I D$ & 4 & 1 & & 0.3 & \\
\hline$P I$ & 0.3 & 1 & & &
\end{tabular}

TABLE 7

COMPARISON BETWEEN PI, PID AND FOPID CONTROLLER PERFORMANCE INDICES

\begin{tabular}{l||c||c||c} 
controllers & Rise period(sec) & $\begin{array}{c}\text { Settling } \\
\text { Period(sec) }\end{array}$ & Peak Overshot \\
\hline FOPID & 0.225 & 0.275 & 0 \\
\hline$P I D$ & 0.6 & 0.9 & 0 \\
\hline PI & 0.65 & 2.75 & 0.025
\end{tabular}

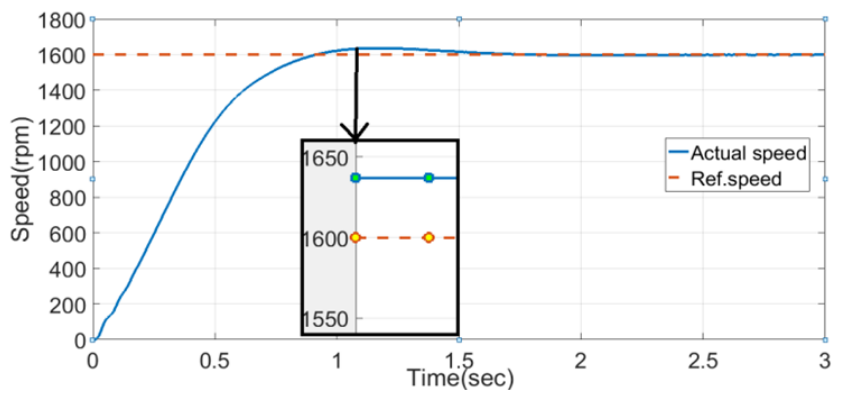

Fig. 16. Speed versus Time with set point speed at $1600 \mathrm{rpm}$ with PI controller

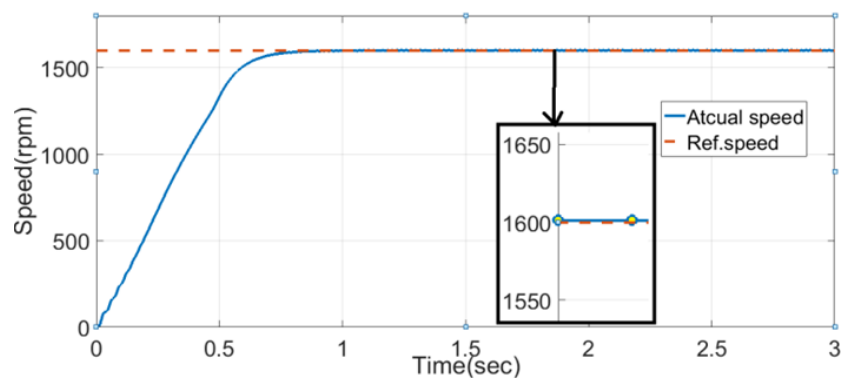

Fig. 17. Speed versus Time with set point Speed at $1600 \mathrm{rpm}$ with PID controller 


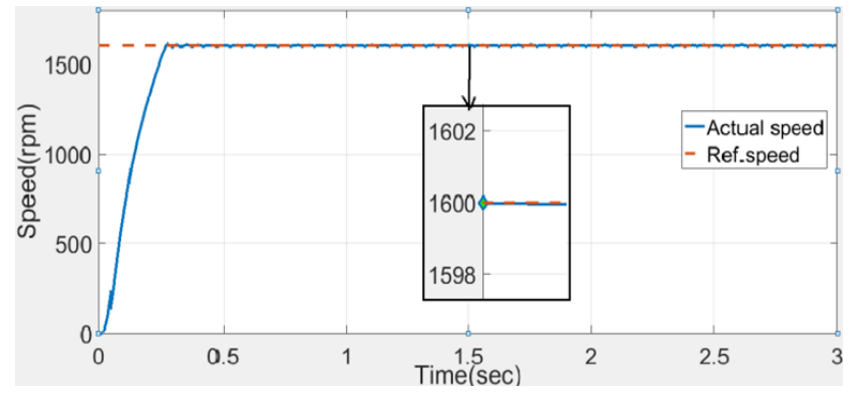

Fig. 18. Speed versus Time with set point Speed at $1600 \mathrm{rpm}$ with FOPID controller

\section{2) Motor operation under loading}

To investigate the system stability operation for the proposed controller a sudden torque load $(\mathrm{Tload}=1 \mathrm{Nm})$ is applied at instant $\mathrm{t}=2 \mathrm{sec}$.

The obtained results are shown in Figures 19:21. The results ensure again the proposed FOPID controller introduced always the better performances which make it favorably recommended instead of other conventional controllers.

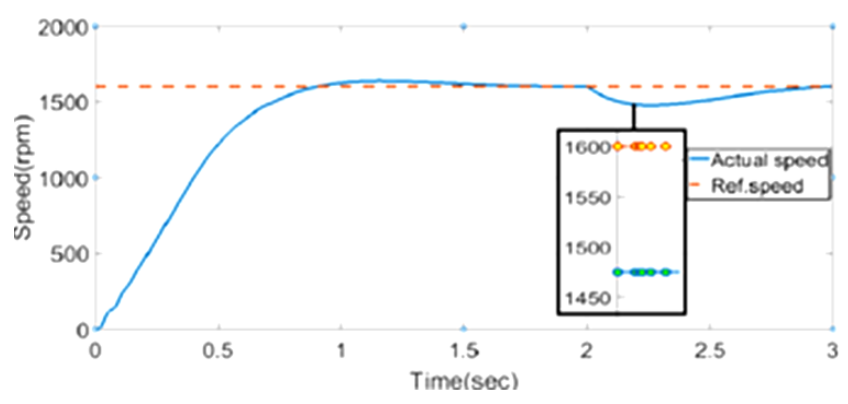

Fig. 19. Speed versus time with set point Speed at $1600 \mathrm{rpm}$ for PI $(\mathrm{Tl}=1 \mathrm{~N} . \mathrm{M}$ at $\mathrm{t}=2 \mathrm{sec})$

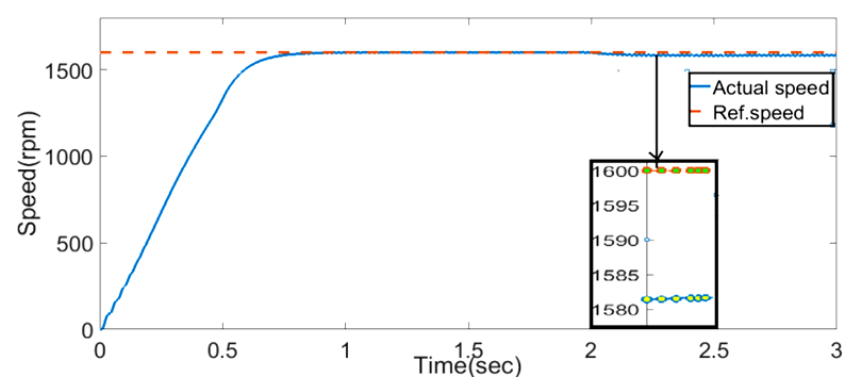

Fig. 20. Speed versus Time with set point Speed at $1600 \mathrm{rpm}$ for PID $\left(T_{L}=1 N . M\right.$ AT T $\left.=2 S E C\right)$

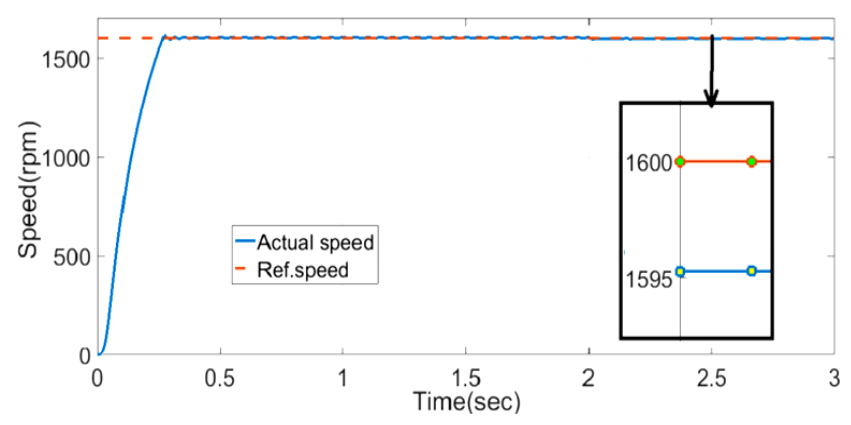

Fig. 21. Speed versus Time with set point Speed at $1600 \mathrm{rpm}$ for FOPID $(\mathrm{TL}=1 \mathrm{~N} . \mathrm{m}$ at $\mathrm{t}=2 \mathrm{sec})$

\section{CONCLUSION}

This paper presented a details study about constant speed control achievement of the induction motors due to their highly important needed in the industrial applications. This is thanks to their several advantages over the conventional dc motors in terms of low cost, low maintenance, high performance, and high power density. The proposed control strategy improved the motor performance using a Fractionalorder PID controller (FOPID). The five important variables coefficients for the proposed controller are named as follows: proportional operator $\left(K_{p}\right)$, integral operator $\left(K_{i}\right)$, derivative operator $K_{d}$ integral of fractional-order $\lambda$ and the derivative of fractional-order $\mu$. The performance of any controller depends mainly on the chosen values of the aforementioned operators $\left(K_{p}, K_{i}, K_{d}, \lambda, \mu\right)$ so one of the main objectives of this paper how to optimize the values of these five parameters to improve the system performance. Actually there are many methods to achieve the optimization problem but a two selected optimizers (Grey Wolf Optimizer, and Nelder-Mead) are chosen in this paper due their nature which make them more suitable for the presented problem. Three cases study of the induction motor integrated with the proposed controllers are simulated based on Matlab SIMULINK and the obtained results are discussed in details. For example in the third case study under no load operation it is found that the settling time is improved from 2.75 to 0.9 in case of using PID controller instead of PI controller. A higher improvement is obtained at using FOPID controller which reached to 0.275. Also it was noted that there is another higher improvement for the rise time from 0.65 to 0.6 and from 0.6 to 0.225 . The same notes for the signal overshoot. Finally it concluded that the obtained results in all the cases ensured that the proposed FOPID controller introduced always the better performances indices which make it favorably recommended instead of other conventional controllers.

\section{APPENDIX}

The following parameters of IM are given in Table 1.

TABLE 1

AC MOTOR PARAMETER [34]

\begin{tabular}{l||c||l}
\multicolumn{1}{c||}{ Parameters } & VALUES & \multicolumn{1}{c}{ UNIT } \\
\hline Rated frequency $F$ & 50 & $\mathrm{~Hz}$ \\
\hline Number of poles $p$ & 4 & \\
\hline Rated voltage $v_{n}$ & 220 & $\mathrm{~V}$ \\
\hline Stator resistance $R s$ & 10.1 & $\Omega$ \\
\hline Rotor resistance $R r$ & 9.8546 & $\Omega$ \\
\hline Rotor inductance Lr & 0.8330 & $\mathrm{H}$ \\
\hline Stator inductance Ls & 0.8330 & $\mathrm{H}$ \\
\hline Mutual inductance Lm & 0.7827 & $\mathrm{H}$ \\
\hline Moment of inertia $\mathrm{J}$ & 0.88 & $\mathrm{~kg} . \mathrm{m}^{2}$
\end{tabular}




\section{AUthors CONTRIBUTION}

Author 1 did the following:

1. Data collection and tools

2. Data analysis and interpretation

3. Investigation

4. Methodology

5. Software

Author 2 did the following:

1. Research idea development

2. Software

3. Methodology

4. Permanent Supervision

Author 3 did the following:

1. Research idea development

2. Methodology

3. Permanent Supervision

4. Drafting the article

5. Project administration

6. Resources

7. Final approval of the version to be published

The corresponding author is responsible for ensuring that the descriptions are accurate and agreed by all authors.

\section{REFERENCES}

[1] OTKUN, O. "Scalar speed control of induction motors with difference frequency." Politeknik Dergisi (2020).

[2] Kouro S., Bernal R., Miranda H., Silva C.A., and Rodriquez J., "HighPerformance Torque and Flux Control for Multilevel Inverter Fed Induction Motors." IEEE Transaction on Power Electronics, 22(6): 2116-2123, (2007).

[3] Dos Santos, T. H., Goedtel, A., da Silva, S. A. O., Suetake, M. "Scalar control of an induction motor using a neural sensor less technique." Electric Power Systems Research 108 (2014): 322-330.

[4] Giri, F. (Ed). AC electric motors control: advanced design techniques and applications. John Wiley, Sons, 2013.

[5] [Chan, T. F., and Shi, K. "Applied intelligent control of induction motor drives". John Wiley, Sons, 2011.

[6] Rajaji, L., Kumar, C., Vasudevan, M. "Fuzzy and ANFIS Based Soft Starter Fed Induction Motor Drive for High Performance Applications" Sathyabama University, India S.K.P. Engineering College, India Vestas RRB India Ltd., India, Vol. 3, No. 4, August 2008.

[7] Mahapatra, S., Daniel, R., Dey, D. N., Nayak, S. K. . "Induction motor control using PSO-ANFIS." Procedia Computer Science 48 (2015): 753 768.

[8] Abdel-Khalik, A. S., Hamdy, R. A., Massoud, A. M., \& Ahmed, S. "Postfault control of scalar (V/f) controlled asymmetrical six-phase induction machines." IEEE Access 6 (2018): 59211-59220

[9] Chun-Chieh W. and Chih-Hsing F. ,"Sensorless Scalar-Controlled Induction Motor Drives With Modified Flux Observer", IEEE Transaction on Energy Conversion, Vol. 18, No. 2, June 2003

[10] Zhang, Z., Y., Bazzi, A. M. "An improved high-performance open-loop V/f control method for induction machines." 2017 IEEE Applied Power Electronics Conference and Exposition (APEC). IEEE, 2017.

[11] Jisha, L. K., Thomas, A. P. "A comparative study on scalar and vector control of Induction motor drives." 2013 International conference on Circuits, Controls and Communications (CCUBE). IEEE, 2013.

[12] Draou, A., Miloud, A., Miloud, Y. "A Variable Gains PI Speed Controller in a Simplified Scalar Mode Control Induction Machine
Drive - Design and Implementation', International Conference Control, Automation and Systems; 27-30 Oct., South Kore, (2010).

[13] Kumar, A, JL, F.D. "A novel self-tuning fuzzy based PID controller for speed control of induction motor drive.", 2013 International Conference on Control Communication and Computing (ICCC). IEEE, 2013.

[14] Azman, A. A., Rahiman, M. H. F., Mohammad, N. N., Marzaki, M. H., Taib, M. N., Ali, M. F. "Modeling and comparative study of PID Ziegler Nichols (ZN) and Cohen-Coon (CC) tuning method for Multi-tube aluminum sulphate water filter (MTAS).", 2017 IEEE 2nd International Conference on Automatic Control and Intelligent Systems (I2CACIS). IEEE, 2017.

[15] Tavakoli, S., Tavakoli, M. "Optimal tuning of PID controllers for first order plus time delay models using dimensional analysis." 2003 4th International Conference on Control and Automation Proceedings. IEEE, 2003

[16] Hambali, N., Masngut, A.,Ishak, A. A., Janin, Z. "Process controllability for flow control system using Ziegler-Nichols (ZN), Cohen-Coon (CC) and Chien-Hrones-Reswick (CHR) tuning methods." 2014 IEEE International Conference on Smart Instrumentation, Measurement and Applications (ICSIMA). IEEE, 2014.

[17] Chiewchitboon, P., Tipsuwanporn, V., Soonthornphisaj, N., Piyarat, W. "Speed control of three-phase induction motor online tuning by genetic algorithm." The Fifth International Conference Engineering Research and Applied Science 4.1 (2015): 278-282 on Power Electronics and Drive Systems, 2003. PEDS 2003. Vol. 1.IEEE, 2003.

[18] Wang, D., Tan, D., Liu, L. "Particle swarm optimization algorithm: an overview." Soft Computing 22.2 (2018): 387-408.

[19] Daniel, E. "Optimum wavelet-based homomorphic medical image fusion using hybrid genetic-grey wolf optimization algorithm." IEEE Sensors Journal 18.16 (2018): 6804-6811.

[20] PID Controller Tuning in Simulink, 1994-2018. [Online].Available:

https://www.mathworks.com/help/slcontrol/gs/automated-tuning-of-simulinkpid-controller-block.html

[21] Abdelwanis, M. I., El-Sehiemy, R. A. "Performance enhancement of split-phase induction motor by using fuzzy-based PID controller." Journal of Electrical Engineering 70.2 (2019): 103-112.

[22] Attia, A. F., Sharaf, A., \& El Sehiemy, R. "Multi-stage fuzzy based flexible controller for effective voltage stabilization in power systems." ISA transactions (2021).

[23] Abdelwanis, M. I., El-Sehiemy, R. A."A fuzzy-based controller of a modified six-phase induction motor driving a pumping system." Iranian Journal of Science and Technology, Transactions of Electrical Engineering 43.1 (2019): 153-165.

[24] Yildiz, A. R."A novel hybrid whale-Nelder-Mead algorithm for optimization of design and manufacturing problems." The International Journal of Advanced Manufacturing Technology 105.12 (2019): 50915104

[25] Shah, P., Agashe, S. "Review of fractional PID controller." Mechatronics 38 (2016): 29-41.

[26] Shitole, N., Dhoot, N. D. "Implementation of Three Phase Induction Motor Control Drive Using PID and FUZZY Technique and Their Comparison." International Journal of Science and Research (IJSR) (2014).

[27] Saleem, A., Soliman, H., Al-Ratrout, S., Mesbah, M. "Design of a fractional order PID controller with application to an induction motor drive." Turkish Journal of Electrical Engineering \& Computer Sciences 26.5 (2018): 2768-2778.

[28] Boukhalfa, G., Belkacem, S., Chikhi, A., Benaggoune, S. "Genetic algorithm and particle swarm optimization tuned fuzzy PID controller on direct torque control of dual star induction motor." Journal of Central South University 26.7 (2019): 1886-1896.

[29] Wasusatein, W., Nittayawan, S., Kongprawechnon, W. "Speed Control Under Load Uncertainty of Induction Motor Using Neural Network Auto-Tuning PID Controller." 2018 International Conference on Embedded Systems and Intelligent Technology \& International Conference on Information and Communication Technology for Embedded Systems (ICESIT-ICICTES). IEEE, 2018.

[30] Bui, H. L., Huang, S., Pham, D. C. Pham. "Modeling and Simulation of Voltage Source Inverter with Voltage Drop and Its Application for Direct Torque Control of Induction Motors." International Journal of Computer and Electrical Engineering (ijcee) (2016).

[31] Tepljakov, A., Petlenkov, E., Belikov, J., Finajev, J. "Fractional-order controller design and digital implementation using FOMCON toolbox for MATLAB." 2013 IEEE conference on computer aided control system design (CACSD). IEEE, 2013. 
[32] Rezaei H., Bozorg-Haddad O., Chu X. "Grey wolf optimization (GWO) algorithm." Advanced Optimization by Nature-Inspired Algorithms. Springer, Singapore, 2018. 81-91.

[33] Corrigan, D. "Characterising the Response of a Closed Loop System." Electronic and Electrical Engineering (2012).

[34] Srikanth dakoju (2021). Closed Loop Speed Control of Induction Motor (PI Control) [Online].Available: https://www.mathworks.com/matlabcentral/fileexchange/51059-closedloop-speed-control-of-induction-motor-pi-control), MATLAB Central File Exchange.

\section{Title Arabic:}

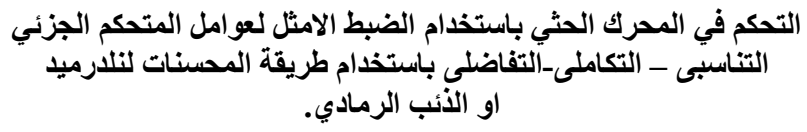

\section{Arabic Abstract:}

يفضل استخدام المحركات الحثية عن محركات التيار المستمر في كثثبر من

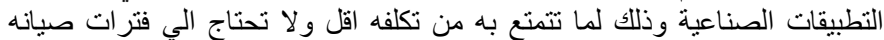

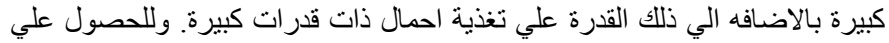

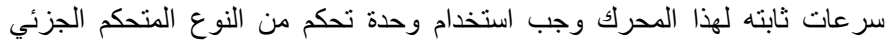

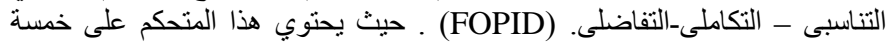

معاملات متغيرات مهمة. يتم تسميتها على النحو التالي: - عامل التشغيل التناسبى (Kp

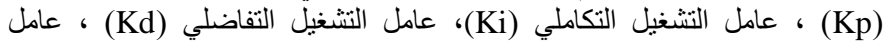

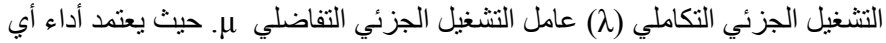

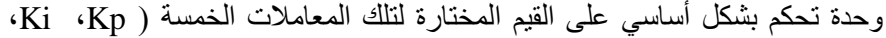
ل خ،Kd

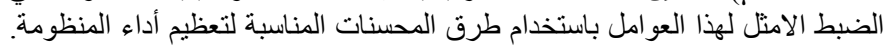

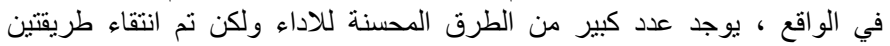

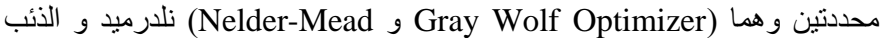
الرمادي وذذلك لانهما اكثر ملائمة لهذه الدر اسة.

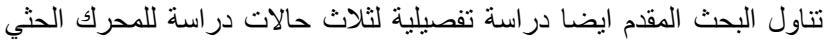

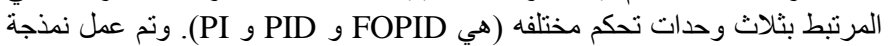

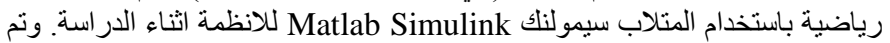

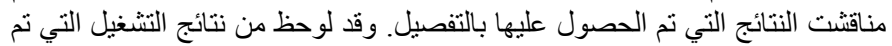

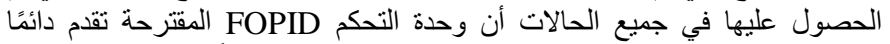
مؤشرات أداء أفضل والتي تجعلنا ان الني نوصى باستخدامها بدلاً من وحدات التحكم

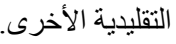

